Research Article

\title{
Chitosan-Derived Magnetic Nanomaterials: Synthesis, Characterization, and Nitrite Adsorption in Water
}

\author{
Tong Liu $\mathbb{D},{ }^{1}$ Jingyi Fu $\mathbb{D}^{1},{ }^{1}$ Dongxia Gou $\mathbb{D}^{1},{ }^{1}$ Yanbo Hu $\mathbb{D}^{1},{ }^{1}$ Qilong Tang $\mathbb{D}^{1},{ }^{1}$ Jun Zhao $\mathbb{D},{ }^{1}$ \\ and Xiaohong $\mathrm{Li}{ }^{2}$
}

${ }^{1}$ College of Food Science and Engineering, Changchun University, Changchun 130118, China

${ }^{2}$ College of Food Engineering, Jilin Engineering Normal University, Changchun 130052, China

Correspondence should be addressed to Jun Zhao; zhaoj70@ccu.edu.cn and Xiaohong Li; lixiaohong@jlenu.edu.cn

Received 17 June 2021; Accepted 8 August 2021; Published 18 August 2021

Academic Editor: Valeri P. Tolstoy

Copyright (c) 2021 Tong Liu et al. This is an open access article distributed under the Creative Commons Attribution License, which permits unrestricted use, distribution, and reproduction in any medium, provided the original work is properly cited.

\begin{abstract}
Nitrite is one of the main pollutants in the water worldwide. In this study, we have applied the reverse suspension crosslinking methodology based on chitosan (CS) and $\mathrm{Fe}_{3} \mathrm{O}_{4}(\mathrm{FeO})$ to synthesize the novel magnetic nanomaterial of chitosan (CS-FeO). The physical and chemical properties of CS-FeO were further characterized by scanning electron microscopy, particle size distribution, thermogravimetry, fluxgate magnetometer, Fourier transform infrared spectroscopy, X-ray diffraction spectroscopy, and energy dispersive spectroscopy. Results revealed that CS-FeO showed high thermal stability in the temperature ranging from 50 to $200^{\circ} \mathrm{C}$. CS-FeO showed high crystallinity and magnetism and was easily and quickly separated from aqueous solution in the presence of an external magnetic field. The molecular structure of CS-FeO showed that the coreshell structure of $\mathrm{CS}-\mathrm{FeO}$ was established with $\mathrm{FeO}$ as the core and $\mathrm{CS}$ as the shell. Furthermore, the adsorption rate of nitrite by $\mathrm{CS}-\mathrm{FeO}$ reached $65.83 \pm 0.76 \%$ under optimal conditions. Moreover, CS-FeO showed high regeneration capability with $\mathrm{Na}_{2} \mathrm{SO}_{4}$ used as the eluent. Our study demonstrated evidently that CS-FeO can be potentially used to remove nitrite from drinking water sources and industrial wastewater, suggesting the promising future of the application of CS-derived magnetic nanomaterials in the areas of environmental protections.
\end{abstract}

\section{Introduction}

With the rapid development of industrialization and urbanization, large amounts of pollutants are released into the natural environments, resulting in environmental pollutions and degradations [1-4]. Nitrite is not only one of the intermediate products in the nitrogen cycle in the natural environment but also one of the main pollutants in the drinking water sources worldwide [5]. The increasing content of nitrite in both the surface water and groundwater has received extensive attention due to its significant impact on human health and ecosystems $[6,7]$. It is well known that nitrite can severely reduce the capability of hemoglobin to exchange oxygen by participating in the interaction of oxygen transport in the body $[8,9]$. Studies have shown that the acute toxicity of nitrite is ten times higher than that of nitrate [10]. The increase of nitrite in the aquatic ecosystem has shown severe detrimental effects on the environment, leading to the acceleration of environmental eutrophication, the imbalance of species distribution in the ecosystem, the growth of a single species, the destruction of the system's material cycle and energy flow, and ultimately the pollution and deterioration of the ecosystem $[11,12]$. However, due to the improper treatment of various industrial and domestic sewages, the incomplete abiotic and nitrification/denitrification processes in the soil have caused a significant increase in the concentration of nitrite in both surface water and groundwater systems such as rivers, lakes, and other major sources of drinking water in the world [13]. In order to remove the nitrite from water, several categories of technologies have been developed, including physical, chemical, electrical, and biological methods, such as adsorption [14-18], ion exchange [19], electrochemistry [20], biological denitrification [21,22], and catalytic reduction $[23,24]$. However, due to its high solubility and easy diffusion 
in water, nitrite is generally difficult to be removed from the environments. At present, biological denitrification and ion exchange are two commonly used treatment methods, which are limited by several disadvantages such as the generation of a large amount of excess sludge and brine during the treatment process, low removal efficiency, and nonreusable treatment materials. Adsorption is now considered as the most promising technology of removing nitrite due to its high reusability of treatment materials, high cost-effectiveness, and flexible design and operation [18]. Among many types of adsorbents, the natural adsorbents have received increasing attention because of their low cost and nearly no pollution in comparison to chemical adsorbents.

Chitosan (CS) is a type of nontoxic natural polymer and low-priced environmental protection material [25]. CS is mainly produced by deacetylation of chitin in the exoskeletons of some animals (i.e., crustaceans and insects) and in the cell walls of plants, algae, and fungi. The chemical name of CS is poly (beta-(1,4)-2-amino-2-deoxy-D-glucose), containing amino cation and showing several beneficial properties such as hydrophilicity, nontoxicity, biodegradability, biocompatibility, and bacteriostasis [26]. CS contains a unique polycation component with a large number of amino and hydroxyl groups located on the surface of its molecular structure. These amino and hydroxyl groups contain lone pair electrons, which chelate with $\mathrm{Cu}^{2+}, \mathrm{CR}^{2+}$, $\mathrm{Cd}^{2+}, \mathrm{Pb}^{2+}$, and other heavy metal ions through coordination to form stable chelates. Therefore, CS shows high selective adsorption for heavy metal ions [25, 27-30].

The CS-derived magnetic nanomaterials are composed of CS polymer matrix and a dispersed phase containing magnetic nanoparticles. Due to their remarkable biological and chemical properties, the CS-derived magnetic nanomaterials have been widely investigated as convenient materials of magnetic carriers [31]. Magnetic nanomaterials have the advantages of extremely high surface area to volume ratio, high adsorption capacity, simple recycling, high reusability and superparamagnetism, and convenient surface modification [32, 33]. However, in practical applications, the magnetic nanomaterials show the disadvantageous characteristics of poor stability, poor biocompatibility, and easy oxidization. These problems could be potentially solved by the CS-derived magnetic nanomaterials obtained by combining both CS and magnetic nanomaterials to maintain the advantages of these two types of materials to compensate the disadvantages of a single material along in the practical application. The magnetic nanomaterials could be separated, recycled, and recycled easily and quickly by the external magnetic field, solving the problem of difficult recycle of the adsorbent CS along. The CS-derived magnetic nanomaterials have already been widely applied in various fields, such as water treatment [34] and antibacterial [35], and used as biomedical carriers $[36,37]$ and active substance carriers $[38,39]$. Studies have shown that CS-derived magnetic nanomaterials have shown significant effects on the treatment of heavy metal ions in water [40]. To date, studies on the treatment of nitrite in water using CS-derived magnetic nanomaterials are lacking.
In our study, we used the reverse suspension crosslinking method based on $\mathrm{CS}$ and $\mathrm{Fe}_{3} \mathrm{O}_{4}(\mathrm{FeO})$ to prepare the $\mathrm{CS}$-derived magnetic nanomaterials (CS-FeO). The molecular structures and the chemical and physical properties of $\mathrm{CS}-\mathrm{FeO}$ were analyzed and characterized by scanning electron microscopy (SEM), energy dispersive spectrum (EDS), particle size distribution analyzer, thermogravimetric analysis (TGA), Fourier transform infrared spectroscopy (FTIR), $\mathrm{X}$-ray diffraction spectroscopy (XRD), and fluxgate magnetometer (FM). Our goals were to use the response surface method (RSM) to optimize the adsorption conditions of nitrite in water by $\mathrm{CS}-\mathrm{FeO}$, including the adsorption time, the amount of adsorbent, and the adsorption temperature. We have also investigated the regeneration conditions of $\mathrm{CS}-\mathrm{FeO}$ to explore the potential application of CS-FeO in the removal of nitrite from the water sources. Our results demonstrated clearly that $\mathrm{CS}-\mathrm{FeO}$ can be potentially used to remove nitrite from drinking water sources and industrial wastewater, indicating the prospective future of the application of CS-derived magnetic nanomaterials in environmental protections.

\section{Materials and Methods}

2.1. Chemicals. Chitosan (deacetylation 85-95\%) was purchased from China Pharmaceutical Group Chemical Reagent Co., Ltd. (Shanghai, China). The iron oxide $\left(\mathrm{Fe}_{3} \mathrm{O}_{4}\right.$; nanograde) was purchased from Sigma Chemical Co., Ltd. (St. Louis, MO, USA). All other chemical reagents of analytical grade were purchased from Beijing Chemical Reagent Factory (Beijing, China).

\subsection{Synthesis of Chitosan-Iron Oxide Magnetic Nanomaterials.} The CS-iron oxide magnetic nanomaterials (CS-FeO) were prepared and characterized using a modified method based on a previous study [41]. The optimal preparation conditions of CS-FeO were identified based on the examination of the nitrite adsorption rate in water under the single-factor experiments. A total of $3 \mathrm{~g}$ of CS was dissolved in $200 \mathrm{~mL}$ of the acetic acid solution (2\%) by stirring to prepare the CS stock solution (1.5\%). To determine the optimal content of $\mathrm{FeO}$ for the synthesis of CS-FeO, a total of $0.20,0.25,0.30,0.35$, and $0.40 \mathrm{~g}$ of $\mathrm{FeO}$ was dissolved into $2 \mathrm{~mL}$ of polyethylene glycol 400 and added to the CS solution $(200 \mathrm{~mL})$, respectively, with the $\mathrm{pH}$ value adjusted to 9.0 . A total of $60 \mathrm{~mL}$ of liquid paraffin used as dispersant was added to the mixture of CS and $\mathrm{FeO}$ by stirring at a constant speed for $20 \mathrm{~min}$ at room temperature. Then, a total of $20 \mathrm{~mL}$ of formaldehyde (i.e., the crosslinking agent) solution was added to the reaction system, stirred constantly at $40^{\circ} \mathrm{C}$ for $30 \mathrm{~min}$, and then heated to $60^{\circ} \mathrm{C}$. Finally, a total of $6 \mathrm{~mL}$ of glutaraldehyde (i.e., the crosslinking agent) solution was added to the reaction system and stirred continuously for $2 \mathrm{~h}$. To determine the optimal $\mathrm{pH}$ value for the synthesis of $\mathrm{CS}-\mathrm{FeO}$, a total of $0.30 \mathrm{~g}$ of $\mathrm{FeO}$ was dissolved into $2 \mathrm{~mL}$ of polyethylene glycol 400 and added to the CS solution $(200 \mathrm{~mL})$, with the $\mathrm{pH}$ value adjusted to 8.0 , $8.5,9.0,9.5$, and 10.0, respectively. A total of $60 \mathrm{~mL}$ of liquid paraffin was added to the mixture of CS and FeO by stirring at a constant speed for $20 \mathrm{~min}$ at room temperature. Then, a 
total of $20 \mathrm{~mL}$ of formaldehyde solution was added to the reaction system, stirred constantly at $40^{\circ} \mathrm{C}$ for $30 \mathrm{~min}$, and then heated to $60^{\circ} \mathrm{C}$. Finally, a total of $6 \mathrm{~mL}$ of glutaraldehyde solution was added to the reaction system and stirred continuously for $2 \mathrm{~h}$. To determine the optimal temperature for the synthesis of CS-FeO, a total of $0.30 \mathrm{~g}$ of $\mathrm{FeO}$ was dissolved into $2 \mathrm{~mL}$ of polyethylene glycol 400 and added to the CS solution $(200 \mathrm{~mL})$, with the $\mathrm{pH}$ value adjusted to 9.0. A total of $60 \mathrm{~mL}$ of liquid paraffin was added to the mixture of CS and $\mathrm{FeO}$ by stirring at a constant speed for $20 \mathrm{~min}$ at room temperature. Then, a total of $20 \mathrm{~mL}$ of formaldehyde solution was added to the reaction system, stirred constantly at $40^{\circ} \mathrm{C}$ for $30 \mathrm{~min}$, and then heated to $50^{\circ} \mathrm{C}, 55^{\circ} \mathrm{C}, 60^{\circ} \mathrm{C}, 65^{\circ} \mathrm{C}$, and $70^{\circ} \mathrm{C}$, respectively. Finally, a total of $6 \mathrm{~mL}$ of glutaraldehyde solution was added to the reaction system and stirred continuously for $2 \mathrm{~h}$. The $\mathrm{CS}-\mathrm{FeO}$ magnetic suspensions obtained by stirring were washed sequentially with petroleum ether and absolute ethanol and then filtered under negative pressure, repeated three times, until the washings were neutral. The filter residue was placed in a flat dish, dried, and ground to obtain the powder of the CS-FeO nanomagnetic materials.

2.3. Calculation of Nitrite Adsorption Rate. The nitrite adsorption rate was determined according to the methods of Sun and Dong [42] with some minor modifications. A total of $25 \mathrm{~mL}$ of sodium nitrite solution $(100 \mathrm{mg} / \mathrm{L})$ was poured into an Erlenmeyer flask containing $200 \mathrm{mg}$ of CS$\mathrm{FeO}$, shaken in the water bath at $120 \mathrm{r} / \mathrm{min}$ and $40^{\circ} \mathrm{C}$ for $5 \mathrm{~h}$. After centrifugation at 2,000 r/min for $10 \mathrm{~min}$ at room temperature, a total of $200 \mu \mathrm{L}$ of the supernatant was collected and placed in a $25 \mathrm{~mL}$ colorimetric tube with a stopper. After the dilution of 50 times, $2 \mathrm{~mL} \mathrm{p}$-sulfamic acid solution was added to mix well for $3-5 \mathrm{~min}$; then, $1 \mathrm{~mL}$ naphthalene ethylenediamine hydrochloride solution was added to the reaction system, and finally, distilled water was added to make the final volume of $25 \mathrm{~mL}$, mixed well, and kept in the dark for $25 \mathrm{~min}$. The absorbance was measured at $540 \mathrm{~nm}$ with a spectrophotometer (T-6vm, Nanjing Feile Instrument Co., Ltd., Jiangsu, China). The nitrite adsorption rate was calculated based on the following equation: nitrite adsorption rate $(\%)=\left[1-\left(A_{1}-A_{2}\right) / A_{0}\right] * 100$, where $A_{1}, A_{2}$, and $A_{0}$ were the absorbance of the sample, the mixture with deionized water, and the blank control, respectively. The calibration curve was obtained by using the standard solutions of sodium nitrite in distilled water and was expressed as the following formula: $y=0.59055 x$ +0.00672 , where $y$ was the absorbance at $540 \mathrm{~nm}$ and $x$ was the content of sodium nitrite $\left(R^{2}=0.9993\right)$.

\subsection{Characterization of the Chemical and Physical Properties of $\mathrm{CS}-\mathrm{FeO}$}

2.4.1. SEM Observation. All samples were observed using an ESEM FEG scanning electron microscope (XL-30, FEI Company, USA). Samples were evenly dispersed on a sample stage covered with a double-sided adhesive and sprayed with gold powder. The accelerated voltage was set to $20.0 \mathrm{kV}$ with each sample observed at $\times 300, \times 5,000$, and $\times 20,000$ magnifications, respectively.
2.4.2. Particle Size Distribution Analysis. Samples (2 g) were dissolved in ultrapure water $(100 \mathrm{~mL})$ to make a suspension solution (2\%). The particle size distribution of each sample was measured by a laser particle size analyzer (Mastersizer 3000, Malvern Instruments Co., Ltd., UK) with a shading rate of $35 \%$ and scattering intensity of $10-20 \%$.

2.4.3. Thermogravimetric Analysis. In the thermogravimetric analysis (TGA), the sample (5 mg) was placed on an aluminum sample plate of the thermogravimetric analyzer (TGA4000, PerkinElmer, USA). Nitrogen (99.99\%) with a flow rate of $30 \mathrm{~mL} / \mathrm{min}$ was used as a carrier gas. The detection temperature was raised from $50^{\circ} \mathrm{C}$ to $800^{\circ} \mathrm{C}$ at a heating rate of $10^{\circ} \mathrm{C} / \mathrm{min}$.

2.4.4. Fluxgate Magnetometer Analysis. In the fluxgate magnetometer analysis (FMA), the sample $(1 \mathrm{~g})$ was placed in a nonmagnetic Eppendorf tube $(1.5 \mathrm{~mL})$ and slowly and repeatedly passed through the induction gantry of the fluxgate magnetometer (Ctm-w, Beijing Zero Magnetic Technology Co., Ltd., Beijing, China) to measure the range of the magnetic strength of the sample.

2.4.5. Energy Dispersive Spectrum Analysis. The microstructure of CS-FeO was observed with a SEM (XL-30, FEI Company, USA) with its energy dispersion spectrum recorded simultaneously.

2.4.6. Fourier Transform Infrared Spectroscopy Analysis. The infrared spectral analysis was performed using an FTIR spectrometer (IR Prestige-21, Shimadzu, Japan). The sample of $2 \mathrm{mg}$ was dried with $200 \mathrm{mg}$ potassium bromide at $105^{\circ} \mathrm{C}$, mixed uniformly, and compacted into a disk for the collection of infrared spectra at $4,000-400 / \mathrm{cm}$. The spectra were recorded with a resolution of $4 / \mathrm{cm}$ and a coaddition of 16 scans, analyzed using IR Solution (Shimadzu Optics Ltd., Japan).

2.4.7. X-Ray Diffraction Spectroscopy Analysis. The X-ray diffraction patterns were recorded on a diffractometer (PW1820, Philips, New York, USA) with a $\mathrm{Cu}-\mathrm{K} \alpha$ radiation for crystalline phase identification. The sample was scanned from $20^{\circ}$ to $80^{\circ}$ and operated at the current of $40 \mathrm{kV} / 40 \mathrm{~mA}$.

2.5. Optimization of Adsorption Conditions of Nitrite by CS$\mathrm{FeO}$. Optimization of adsorption conditions of nitrite by CS$\mathrm{FeO}$ was performed according to a previously reported method of Lv et al. [43] with some minor modifications. First, the single-factor experiments of the nitrite adsorption were conducted. To determine the optimal content of CS$\mathrm{FeO}$, a total of $25 \mathrm{~mL}$ of sodium nitrite solution $(100 \mathrm{mg} / \mathrm{L})$ was added into the Erlenmeyer flask containing 160, 200, 240,280 , and $320 \mathrm{mg}$ of CS-FeO, respectively, with the reactions shaken in a water bath at $120 \mathrm{r} / \mathrm{min}$ and $50^{\circ} \mathrm{C}$ for $5 \mathrm{~h}$. To determine the optimal adsorption temperature, a total of $25 \mathrm{~mL}$ of sodium nitrite solution $(100 \mathrm{mg} / \mathrm{L})$ was added into the Erlenmeyer flask containing $240 \mathrm{mg}$ of $\mathrm{CS}-\mathrm{FeO}$, with the reactions shaken in a water bath at $120 \mathrm{r} / \mathrm{min}$ for $5 \mathrm{~h}$ at $30^{\circ} \mathrm{C}, 40^{\circ} \mathrm{C}, 50^{\circ} \mathrm{C}, 60^{\circ} \mathrm{C}$, and $70^{\circ} \mathrm{C}$, respectively. To determine the optimal adsorption time, a total of $25 \mathrm{~mL}$ of sodium nitrite solution $(100 \mathrm{mg} / \mathrm{L})$ was added into the 
Erlenmeyer flask containing $240 \mathrm{mg}$ of CS-FeO, with the reactions shaken in a water bath at $120 \mathrm{r} / \mathrm{min}$ and $50^{\circ} \mathrm{C}$ for $3,4,5,6$, and $7 \mathrm{~h}$, respectively. After centrifugation at $3,000 \mathrm{r} / \mathrm{min}$ for $10 \mathrm{~min}$ at room temperature, the supernatant $(200 \mu \mathrm{L})$ was placed in a $25 \mathrm{~mL}$ colorimetric tube with a stopper. After the dilution of 50 times, $2 \mathrm{~mL} \mathrm{P}$-sulfanilic acid solution were added to mix well for 3-5 min; then, $1 \mathrm{~mL}$ naphthalene ethylenediamine hydrochloride solution was added to the reaction, and finally, distilled water was used to make the final volume of $25 \mathrm{~mL}$, mixed well and kept in the dark for $25 \mathrm{~min}$. The absorbance was measured with a spectrophotometer at $540 \mathrm{~nm}$ to determine the nitrite adsorption rate. Then, a three-factor three-level RSM analysis was performed based on the results of the single-factor experiments using the Box-Behnken central combination test design. The nitrite adsorption rate $(Y)$ was the response value with three response factors, including the amount of adsorbent (factor $A$ ), the adsorption temperature (factor $B$ ), and adsorption time (factor $C$ ).

2.6. Regeneration of $\mathrm{CS}-\mathrm{FeO}$. A regeneration test of $\mathrm{CS}-\mathrm{FeO}$ was carried out based on the optimal adsorption conditions. The adsorbed CS-FeO was precipitated by an external magnetic field, and the supernatant was removed. A total of $25 \mathrm{~mL}$ of $\mathrm{NaCl}(1 \mathrm{M}), \mathrm{NaSO}_{4}(1 \mathrm{M})$, and $\mathrm{NaOH}(1 \mathrm{M})$ solutions was added as eluents for elution, shaken at $35^{\circ} \mathrm{C}$ for $2 \mathrm{~h}$, respectively. After the eluent was removed, the fixed concentration of sodium nitrite solution was added to readsorb with the adsorption rate calculated again and compared with that prior to the regeneration. The regeneration experiments were repeated 6 times to evaluate the adsorption effect.

2.7. Statistical Analysis. All experiments were performed thrice, and data were presented as mean \pm standard deviation. Differences between groups of samples were evaluated by analysis of variance (ANOVA) using SPSS v.25.0 software (SPSS Inc., Chicago, IL, USA). Significant differences among treatments were evaluated using Duncan's multiple range test $(P<0.05)$.

\section{Results and Discussion}

\subsection{Physical and Chemical Properties of CS-FeO}

3.1.1. Synthesis of CS-FeO. The optimal synthesis parameters of the CS-FeO included $\mathrm{pH}$ value of $9.5, \mathrm{FeO}$ content of $0.30 \mathrm{~g}$, and temperature at $65^{\circ} \mathrm{C}$. Under these conditions, the adsorption rate of nitrite reached $58.07 \%$. Studies have shown that $\mathrm{CS}-\mathrm{FeO}$ has been widely synthesized to carry out various biological functions. For example, Bharathi et al. reported the preparation of $\mathrm{CS}-\mathrm{FeO}$ nanocomposite using rutin with a facile greener route [41]. Results revealed that the prepared nanoparticles showed potential antibacterial activity against both Gram-positive and Gram-negative bacteria [41]. Similarly, Soares et al. prepared CS-FeO nanoparticles of different molecular weights by chemical precipitation and thermal decomposition and further investigated the thermal and magnetic properties of the synthesized materials [44]. Furthermore, Hastak et al. applied the copre- cipitation technique to synthesize and characterize the superparamagnetic CS-FeO nanoparticles to show its antioxidant properties [45]. Moreover, Nehra et al. synthesized chitosan-iron oxide particles by coprecipitation technology and further assessed their antibacterial and antifungal activities [46]. However, the reports on the treatment of nitrite in water by $\mathrm{CS}-\mathrm{FeO}$ nanoparticles are still lacking. We prepared $\mathrm{CS}-\mathrm{FeO}$ using the reverse suspension crosslinking methodology to further investigate its adsorption properties of nitrite in water.

3.1.2. SEM Observation. The microscopic morphological characteristics of $\mathrm{CS}, \mathrm{FeO}$, and $\mathrm{CS}-\mathrm{FeO}$ were analyzed by SEM (Figure 1). Results revealed that CS showed a smooth surface and no voids (Figures 1(c), 1(f), and 1(i)), while many regular particles (i.e., mainly round crystals) were observed on the surface of FeO (Figures 1(a), 1(d), and $1(\mathrm{~g}))$. CS-FeO showed an uneven surface (Figures 1(b), 1(e), and 1(h)). Compared with $\mathrm{CS}$ and $\mathrm{FeO}$, the surface characteristics of $\mathrm{CS}-\mathrm{FeO}$ were more suitable for adsorbing target substances. Specifically, a large amount of granular substances was observed on the surface of CS-FeO, which was attributed to the $\mathrm{FeO}$ embedded in the CS matrix. Through the package of the matrix, the particles showed irregular shapes, mainly rhombus and ellipse. Similar findings of these surface characteristics were also reported in CS-derived magnetic materials [27]. However, the CS-FeO magnetic nanoparticles synthesized by Bharathi et al. [41] showed agglomerated rod-like grains. These differences may be caused by the different synthetic materials used and methods of synthesizing the CS-FeO. It was noted that the sizes of $\mathrm{Fe}_{3} \mathrm{O}_{4}$ particles (Figure $1(\mathrm{~g})$ ) and the CS-FeO nanoparticles (Figure 1(h)) were different. This was due to the random crosslinking and loading processes between CS and $\mathrm{FeO}$ during the synthesis of CS-FeO, while the sizes of $\mathrm{FeO}$ particles were in the range of $0.1-10 \mu \mathrm{m}$.

3.1.3. Particle Size Distribution Analysis. The particle size distribution of each product is shown in Figure 2. The particle size distribution of CS was uniform and in accordance with normal distribution, while the particle size distributions of both $\mathrm{FeO}$ and $\mathrm{CS}-\mathrm{FeO}$ were not uniform. The median $D_{50}$ values for CS-FeO and CS were $72.18 \mu \mathrm{m}$ and $85.38 \mu \mathrm{m}$, respectively. The specific surface area of CS-FeO was much larger $\left(170.3 \mathrm{~m}^{2} / \mathrm{kg}\right)$ than that of CS $\left(50.69 \mathrm{~m}^{2} / \mathrm{kg}\right)$, indicating that CS-FeO showed more suitable surface characteristics for the adsorption of target substances than those of CS. Therefore, it was reasonable to speculate that $\mathrm{CS}-\mathrm{FeO}$ could be an appropriate candidate of adsorbents for treating nitrite in water sources. Varied results were reported by Cheng et al. [47] who synthesized rod-shaped $\mathrm{FeO}$ nanoparticles with different sizes ranging from 50 to $120 \mathrm{~nm}$, while the magnetic nanoparticles with average diameter less than $10 \mathrm{~nm}$ of the precipitate were produced by the inverse microemulsion method $[48,49]$. These inconsistent results were probably due to the fact that raw materials of CS used in our study were not at nanograde. 


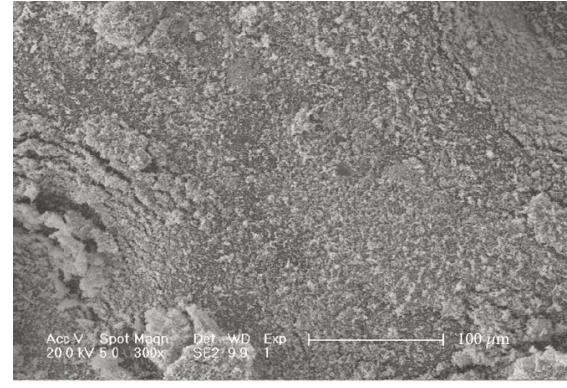

(a)

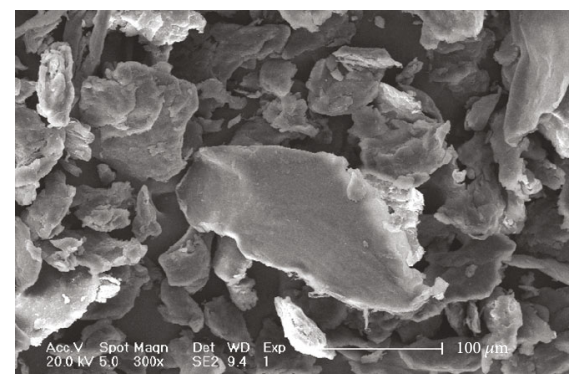

(c)

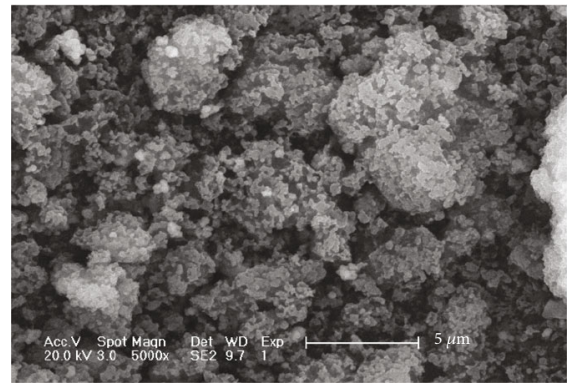

(e)

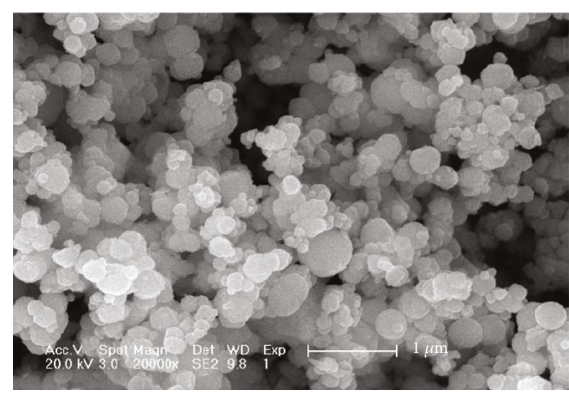

(g)

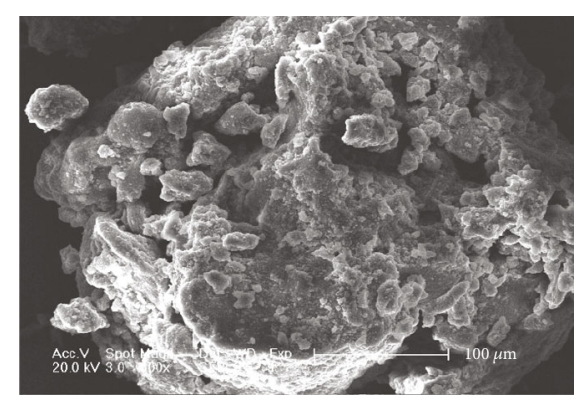

(b)



(d)

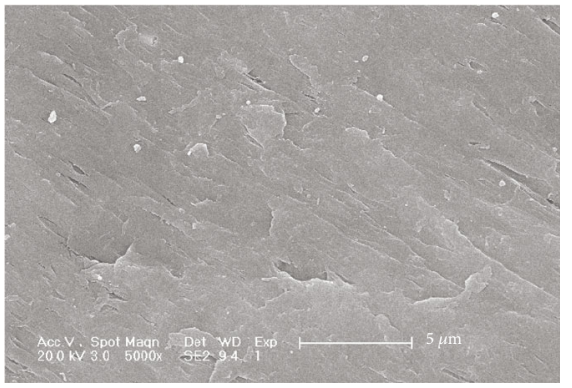

(f)

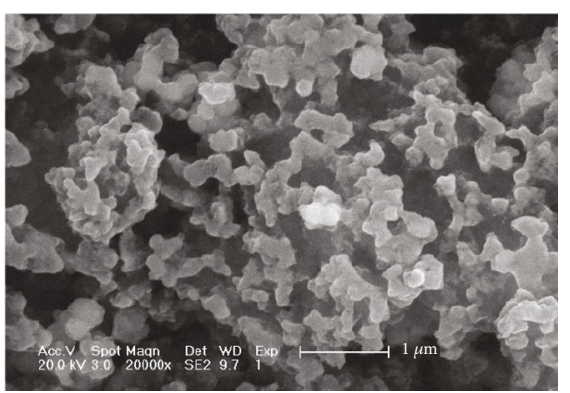

(h)

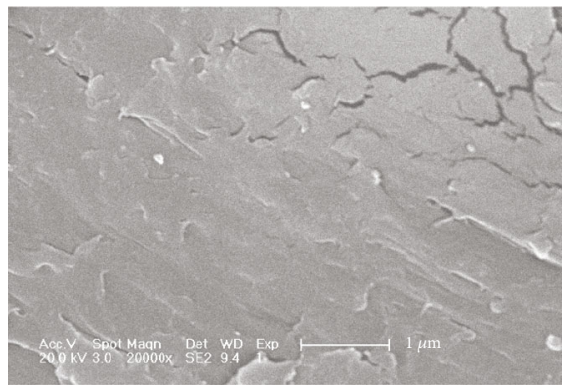

(i)

Figure 1: SEM images of ( $a, d, g)$ iron oxide, $(c, f, i)$ chitosan, and (b, e, h) CS-FeO with a sample thickness of $\sim 0.1 \mu \mathrm{m} . \times 300 \mathrm{magnification}$ in (a)-(c); $\times 5,000$ in (d)-(f); $\times 20,000$ in (g)-(i). 


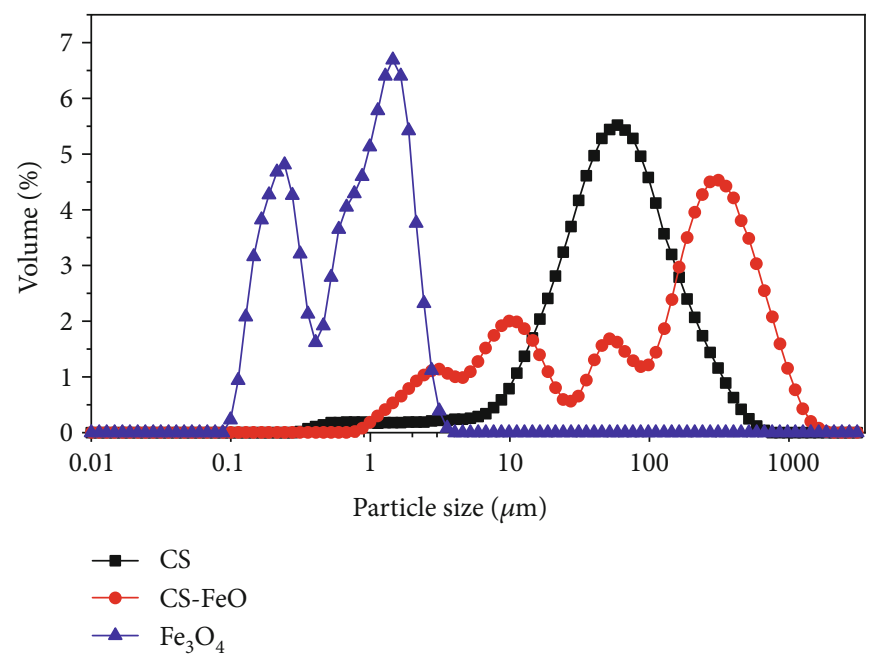

Figure 2: Particle size distribution of iron oxide, chitosan, and CS-FeO.

3.1.4. Thermogravimetric Analysis. Both thermogravimetric analysis (TGA) and derivative thermogravimetric analysis (DTGA) are generally used to monitor the physicochemical changes of polymers. In our study, the results of thermal stability of the samples assessed by TGA and DTGA revealed that $\mathrm{FeO}$ showed a little weight loss as temperature increased from 50 to $800^{\circ} \mathrm{C}$, while CS showed slightly water loss from 50 to $270^{\circ} \mathrm{C}$ but the most severe weight loss at $295^{\circ} \mathrm{C}$ (Figure 3). CS-FeO lost some water from 50 to $201^{\circ} \mathrm{C}$ with the most weight loss at $234^{\circ} \mathrm{C}$. The main reason for the weight loss at both $234^{\circ} \mathrm{C}$ and $295^{\circ} \mathrm{C}$ was probably due to the depolymerization and pyrolysis of glycosides in CS [50]. These results revealed that CS-FeO showed high thermal stability than $\mathrm{CS}$ in the temperature range of 50 to $200^{\circ} \mathrm{C}$, which was sufficient for the application of CS-FeO in water treatment. Similar findings were reported previously, showing the high thermal stability of CS magnetic nanoparticles at temperature range of 80 to $200^{\circ} \mathrm{C}$ [27].

3.1.5. Fluxgate Magnetometer Analysis. The results of magnetic intensity of each sample measured with a fluxgate magnetometer (FM) showed that CS was nearly nonmagnetic, while the magnetic strength of $\mathrm{FeO}$ and $\mathrm{CS}-\mathrm{FeO}$ ranged from -0.5 to $1.8 \mathrm{nT}$ and from -1.0 to $4.0 \mathrm{nT}$, respectively (Figure 4). Compared with $\mathrm{FeO}$, the magnetic strength of $\mathrm{CS}-\mathrm{FeO}$ was significantly improved. This was the first time that the significant improvement in the magnetic strength of CS-FeO was reported in our study. Studies have shown that a value of $5.79 \mathrm{emu} / \mathrm{g}$ for the saturation magnetization of the magnetic properties of CS nanoparticles was measured by a vibrating sample magnetometer (VSM) [27]. This value was far less than that reported for $\mathrm{FeO}$ (36.941 emu/g) by Li et al. [51]. The magnetic saturation intensity of the CS magnetic adsorbent prepared by $\mathrm{Vu}$ et al. [52] and Cao et al. [53] was $23.7 \mathrm{emu} / \mathrm{g}$ and $17.1 \mathrm{emu} / \mathrm{g}$, respectively, both of which were less than the value of $\mathrm{FeO}$ measured in our study. Generally, it is expected that the magnetic value of $\mathrm{Fe}_{3} \mathrm{O}_{4}$ is higher than that of CS-FeO. These inconsistent results revealed in our study may be caused by the different synthesizing methods of the nanomaterials in these studies. Specifically, in our study, there was a long period of high-speed stirring of the reaction system during the synthesis process, which probably increased the paramagnetism of $\mathrm{CS}-\mathrm{FeO}$, leading to higher magnetic strength in $\mathrm{CS}-\mathrm{FeO}$ than that in FeO. Consequently, under the action of an external magnetic field, CS-FeO was easily and quickly separated from the aqueous solution (Figure 4). These results revealed that $\mathrm{CS}-\mathrm{FeO}$ showed sound magnetic separation, indicating that CS-FeO can be easily separated and recovered in the practical applications. Therefore, the potential use of $\mathrm{CS}-\mathrm{FeO}$ as an adsorbent could significantly reduce the cost of nitrite treatment, solving the problem in the traditional methods that the materials of nitrite treatment cannot be recycled.

\subsection{Spectroscopic Characterization of $\mathrm{CS}-\mathrm{FeO}$}

3.2.1. Energy Dispersive Spectrum Analysis. The energy dispersive spectrum (EDS) layered images observed under SEM $(\times 2,000)$ and the spectrogram results of CS-FeO are shown in Figure 5. Results showed that CS-FeO contained a clear core of Fe (Figures 5(a) and 5(b)), while elements carbon (C) and oxygen (O) (Figures 5(c) and 5(d)) formed a shell outside the core. Based on the EDS of CS-FeO, the proportions of the surface elements of $\mathrm{CS}-\mathrm{FeO}$ were $\mathrm{C}$ (66.51\%), O (29.89\%), and $\mathrm{Fe}(3.60 \%)$. The positions of two $\mathrm{Fe}$ characteristic peaks in the spectrum indicated the existence of $\mathrm{FeO}$ in the sample (Figure 5(e)). The presence of CS polymer in the prepared nanocomposite materials was further supported by the detection of elements $\mathrm{C}$ and $\mathrm{O}$ in the EDS. These results indicated that $\mathrm{CS}-\mathrm{FeO}$ contained a core-shell structure with $\mathrm{FeO}$ as the core and CS as the shell. This structure was expected to enhance the molecular stability of CS-FeO and further enhance its stability in practical application as well.

3.2.2. FTIR Analysis. The FTIR spectra of CS, FeO, and CS$\mathrm{FeO}$ (Figure 6) showed that the structure of the CS 


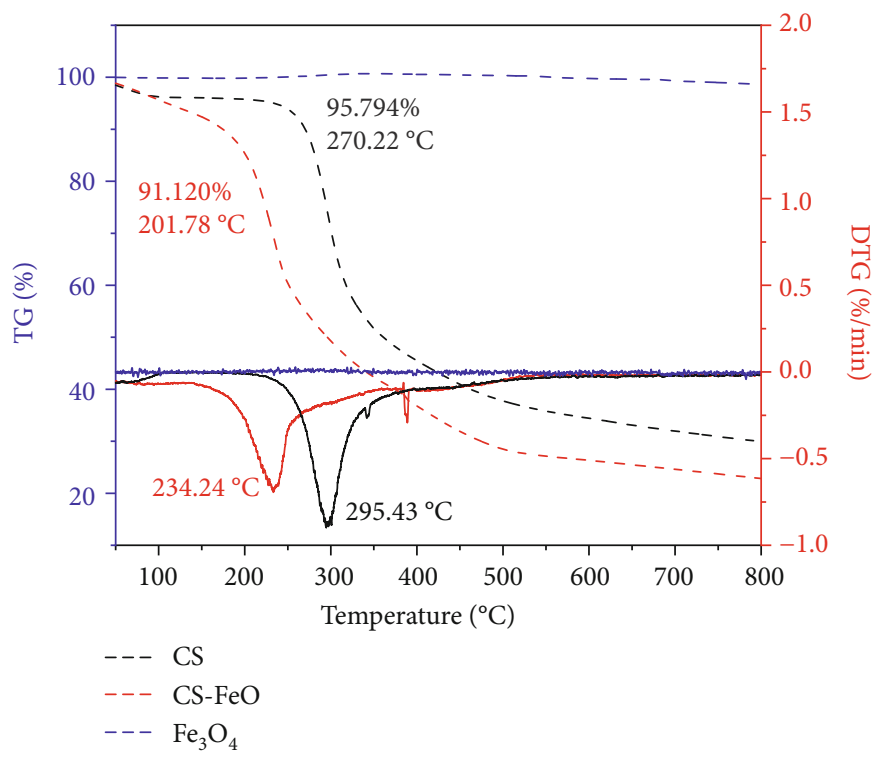

FIGURE 3: Thermogravimetry (TG) and derivative thermogravimetry (DTG) of iron oxide, chitosan, and CS-FeO.

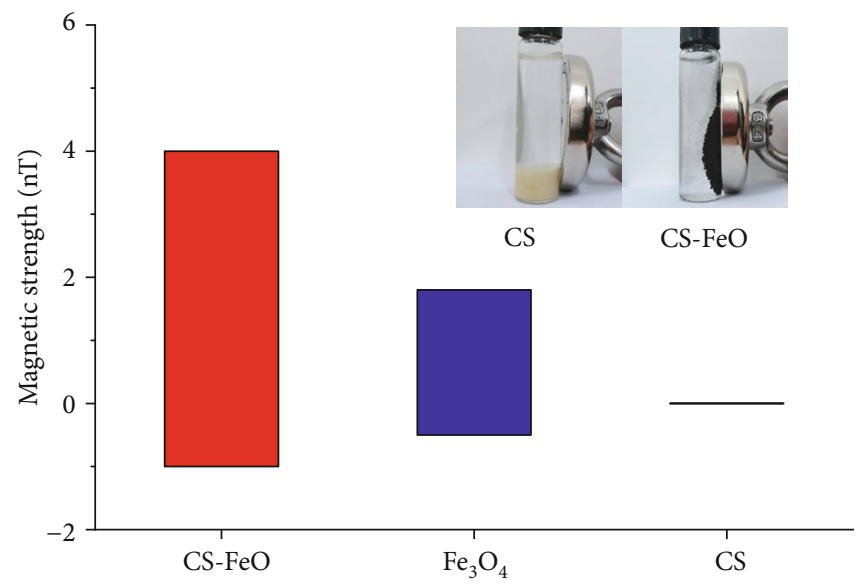

FIGURE 4: Magnetic strength of iron oxide, chitosan, and CS-FeO based on fluxgate magnetometer analysis. The inset shows the separation of CS and CS-FeO in the aqueous solutions in the presence of an external magnetic field: the left vial contains an aqueous solution of CS with nitrite adsorbed and the right vial contains the aqueous solution of CS-FeO with nitrite adsorbed showing the black particles of CS-FeO quickly attracted to the vial wall.

functional group in CS-FeO maintained with the addition of $\mathrm{FeO}$. These results were consistent with those reported previously showing the consistency between the infrared spectra of CS and CS-derived magnetic materials, indicating that the structure of CS was not altered during the synthesis of CS$\mathrm{FeO}[27,41]$. Based on these results, it was predicted that the functional groups of CS were not interrupted once complexed with metal ions ( $\mathrm{FeO}$ ). The absorption peaks of $\mathrm{CS}$ and $\mathrm{CS}-\mathrm{FeO}$ near $3,450 \mathrm{~cm}^{-1}$ was previously designated as $\mathrm{O}-\mathrm{H}$ stretching vibration [54], while the $\mathrm{N}-\mathrm{H}$ and $\mathrm{N}-\mathrm{O}$ stretching vibrations were located around $1,660 \mathrm{~cm}^{-1}$ [55]. The absorption peaks of CS and CS-FeO near $1,375 \mathrm{~cm}^{-1}$ and $1,080 \mathrm{~cm}^{-1}$ were mainly vibrations of $\mathrm{C}-\mathrm{O}$ and $\mathrm{C}-\mathrm{C}$ and bending vibrations of $\mathrm{C}-\mathrm{C}-\mathrm{H}$ and $\mathrm{C}-\mathrm{O}-\mathrm{H}$, respectively $[56,57]$. The absorption peak at $585 \mathrm{~cm}^{-1}$ was determined as the characteristic absorption peak of $\mathrm{FeO}$ [58]. In our study, an absorption peak was observed at $572 \mathrm{~cm}^{-1}$ (Figure 6), indicating that $\mathrm{FeO}$ was successfully incorporated into the structure of CS-FeO. In the spectrum of CS-FeO, a new absorption peak was observed at $1,568 \mathrm{~cm}^{-1}$, which was the characteristic peak of -NHCO. These results suggested that the $\mathrm{NH}_{2}$ of CS was opened and crosslinked during the synthesis process, forming the core-shell structure of CS-FeO [27]. In our study, significant changes in the peak shape and signal intensity of CS and CS-FeO were observed in the range of $2,000-800 \mathrm{~cm}^{-1}$ (Figure 6). These changes were probably due to the decrease of the single substance content ratio after the $\mathrm{CS}$ and $\mathrm{FeO}$ were mixed.

3.2.3. XRD Analysis. The XRD patterns of CS, FeO, and CS$\mathrm{FeO}$ are shown in Figure 7. As a type of amorphous polymer, the diffraction pattern of CS was not clearly observed to 


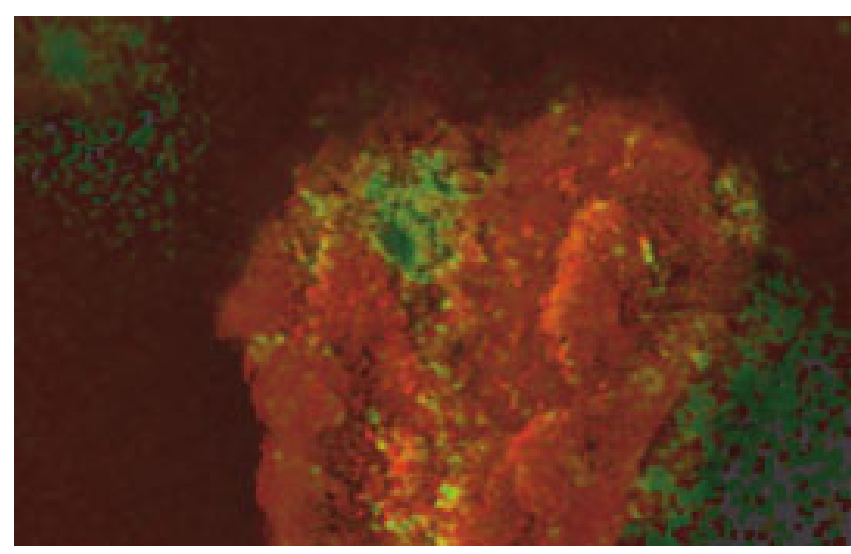

(a)

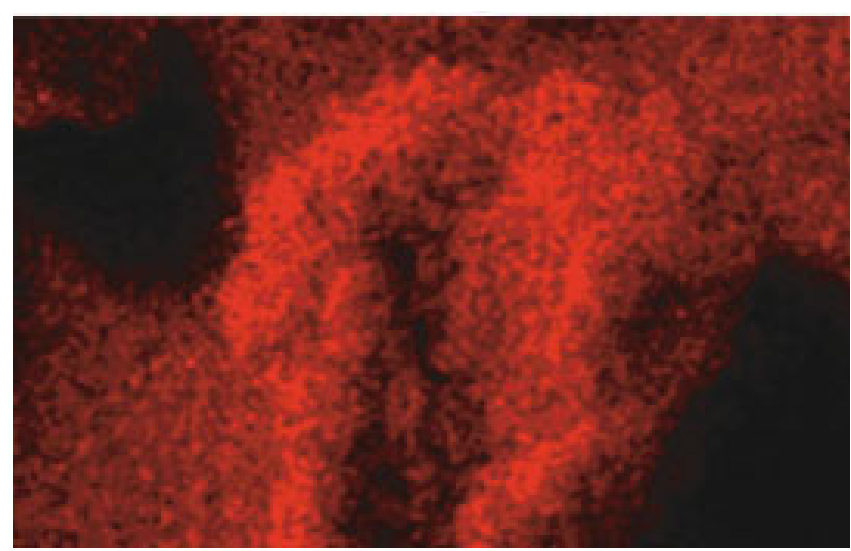

(c)

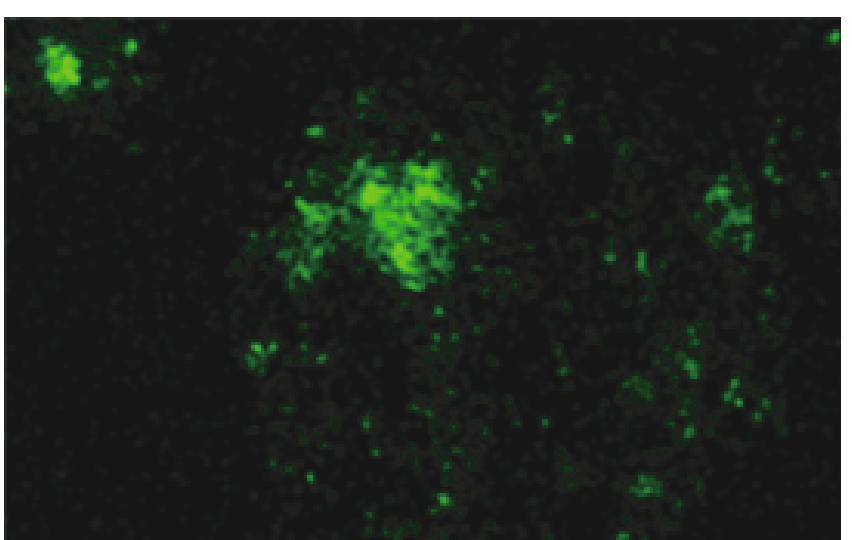

(b)

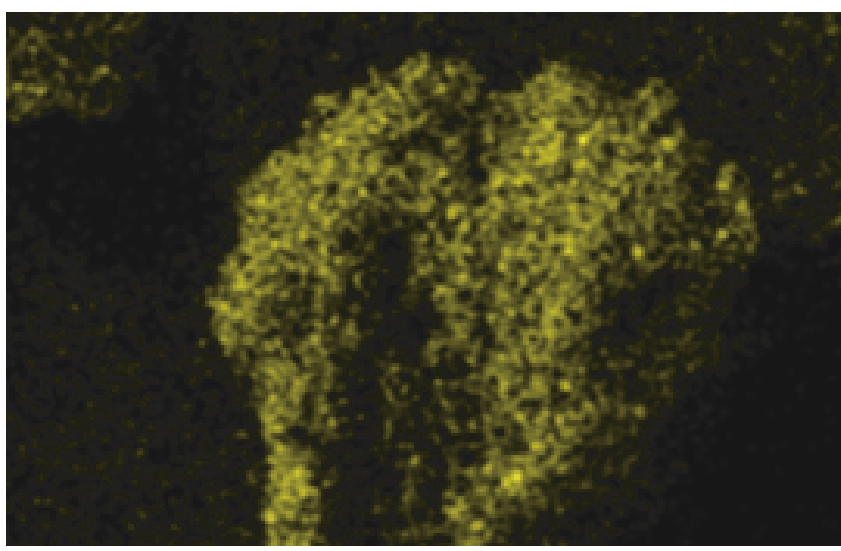

(d)

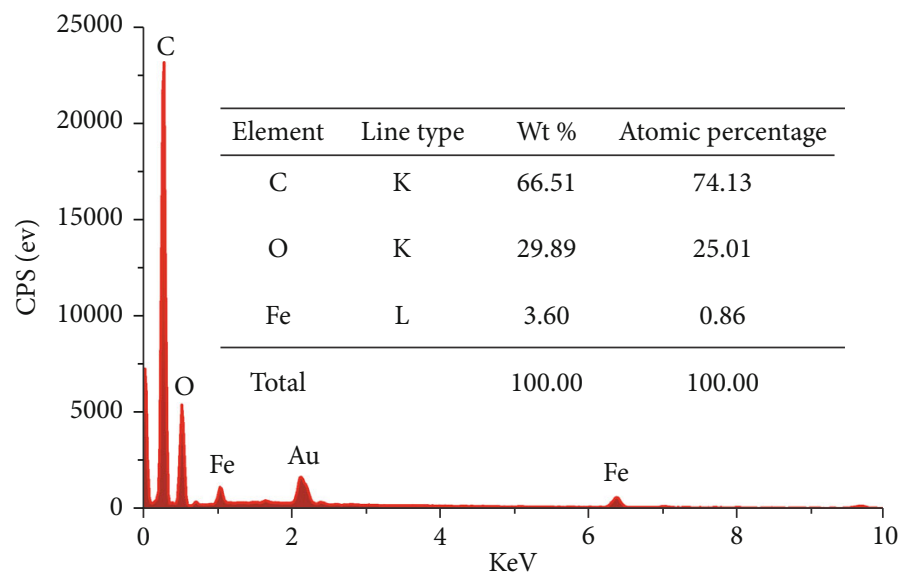

(e)

Figure 5: The energy dispersive spectrum (EDS) images observed under SEM $(\times 2,000)$ of layered structures of (a) CS-FeO, (b) Fe, (c) carbon, and (d) oxygen and the spectrogram of (e) CS-FeO. The green portion represents Fe, red portion represents carbon (C), and yellow portion represents oxygen $(\mathrm{O})$.

show the significant diffraction peak at $2 \theta=28.24^{\circ}$, which was attributed to the molecular hydrogen bonding in CS [59]. A total of 6 evident diffraction peaks were observed in the FeO diffraction pattern. Compared with the available data kept at the Joint Committee on Powder Diffraction Standards (JCPDC) database (PDF No. 65-3107), these 6 diffraction peaks of $\mathrm{FeO}$ were identified as $30.08^{\circ}, 35.54^{\circ}$, $43.16^{\circ}, 53.59^{\circ}, 57.69^{\circ}$, and $62.71^{\circ}$ corresponding to (220),
(311), (400), (422), (511), and (440), respectively. No evident impurity peaks were observed in the diffraction pattern, while the 6 diffraction peaks show clear peak shapes and high intensity, indicating that $\mathrm{CS}-\mathrm{FeO}$ was of high purity and crystallinity. The diffraction pattern of CS-FeO was similar to that of $\mathrm{FeO}$, but showing weakened intensity of the diffraction peaks, indicating that CS-FeO was of high crystallinity with the crystal structure of CS-FeO mainly derived 


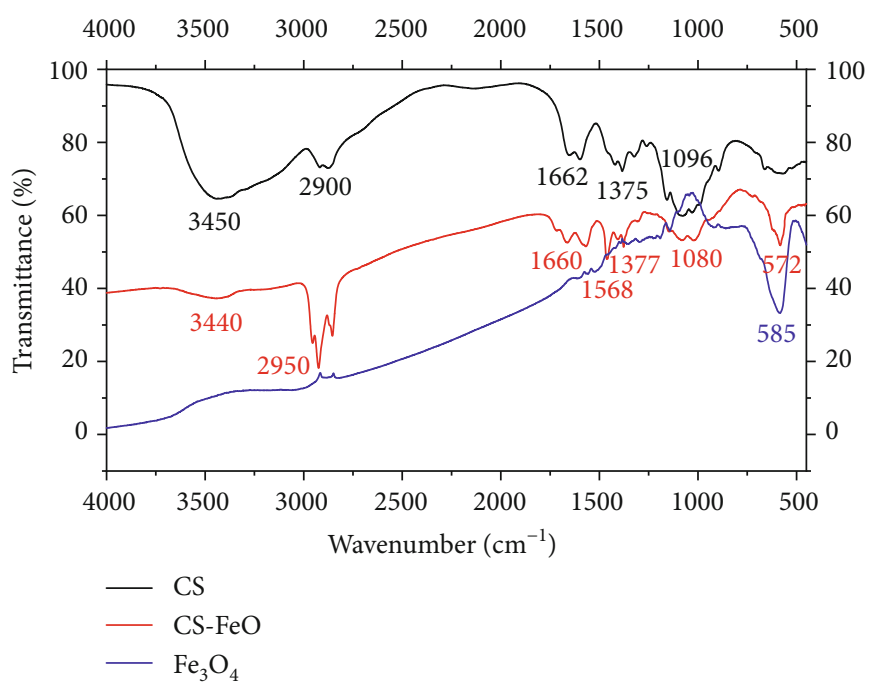

FIgURE 6: FTIR spectra of iron oxide, chitosan, and CS-FeO.

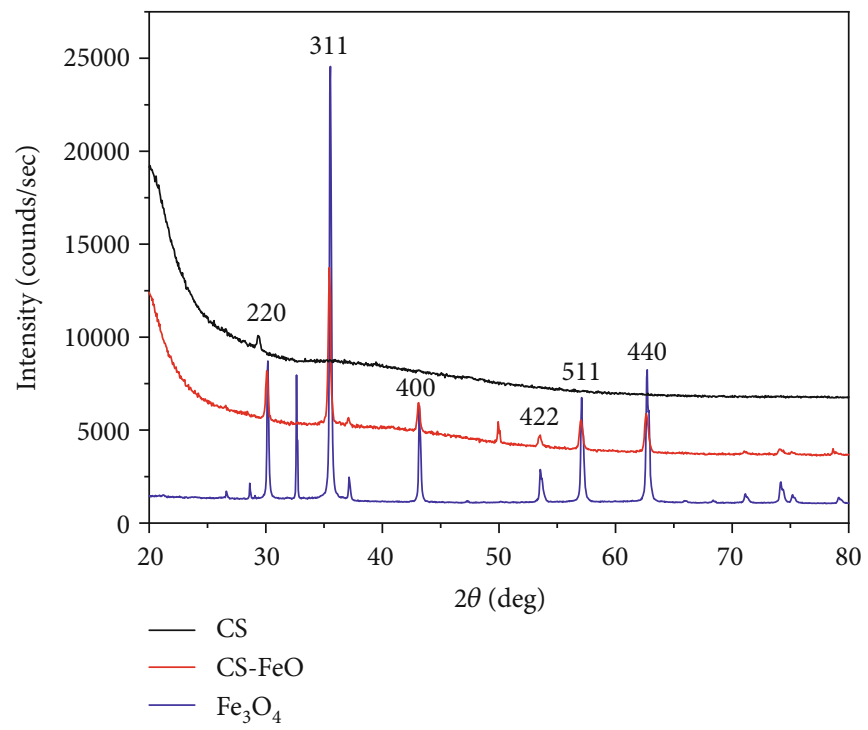

FIgURE 7: XRD patterns of iron oxide, chitosan, and CS-FeO.

from $\mathrm{FeO}$, while the intramolecular hydrogen bonding force in amino group $\left(-\mathrm{NH}^{2}\right)$ of $\mathrm{CS}$ weakened the crystallinity of synthetic materials [60].

\subsection{Optimization of Adsorption Conditions of Nitrite by CS-FeO}

3.3.1. Establishment of Mathematical Model and Significance Test. The Box-Behnken central composite design was adopted to establish the mathematical model and to conduct the significance test of the optimal adsorption condition of nitrite by $\mathrm{CS}-\mathrm{FeO}$. Based on the results of the single-factor tests, the RSM analysis of three factors and three levels was conducted. Specifically, high adsorption rates were observed at the following conditions: 200, 240, and $280 \mathrm{mg}$ of CS-FeO, $40^{\circ} \mathrm{C}, 50^{\circ} \mathrm{C}$, and $60^{\circ} \mathrm{C}$ of adsorption temperature, and 4,5 , and $6 \mathrm{~h}$ of adsorption time. These parameters were chosen to further conduct the RSM analysis. The results of experimental designs based on the central combination test design principle, the ANOVA, and the reliability analysis of regression model are given in Tables $1-3$, respectively.

The best adsorption rates $(\sim 63 \%-66 \%)$ of nitrite by CS$\mathrm{FeO}$ were obtained under $240 \mathrm{mg}$ of CS-FeO at $50^{\circ} \mathrm{C}$ and $5 \mathrm{~h}$ (Table 1). Multiple regression fitting was performed with the results assessed based on both ANOVA and significance test (Table 2) to obtain the binary regression equation with the nitrite adsorption rate $(Y)$ as the objective function and the coded value of each condition: $Y=64.19-1.13 A-1.58$ $B+1.46 C-0.25 A B-0.29 A C-1.30 B C-8.10 A^{2}-14.18 B^{2}$ $-5.41 C^{2}$. These results indicated that the regression model performed to a highly significant level $(P<0.01)$, while the error term was not significant, suggesting that the established regression equation showed a sound fit with the 
TABLE 1: Design and results of the Box-Behnken experiments of nitrite adsorption by CS-FeO based on the amount of adsorbent (factor $A$ ), the adsorption temperature (factor $B$ ), and adsorption time (factor $C$ ) as the response factors.

\begin{tabular}{lcccc}
\hline Sequence & Adsorbent $(\mathrm{mg})$ & Adsorption temperature $\left({ }^{\circ} \mathrm{C}\right)$ & Adsorption time $(\mathrm{h})$ & Adsorption rate $(\%)$ \\
\hline 1 & 240 & 40 & 4 & 4 \\
2 & 240 & 60 & 5 & 42.34 \\
3 & 240 & 50 & 5 & 64.34 \\
4 & 200 & 60 & 5 & 41.66 \\
5 & 240 & 50 & 4 & 65.63 \\
6 & 280 & 50 & 5 & 47.40 \\
7 & 200 & 40 & 5 & 43.31 \\
8 & 240 & 50 & 5 & 63.03 \\
9 & 240 & 50 & 6 & 64.40 \\
10 & 240 & 60 & 6 & 42.26 \\
11 & 240 & 40 & 5 & 49.00 \\
12 & 240 & 50 & 5 & 63.54 \\
13 & 280 & 40 & 5 & 42.66 \\
14 & 280 & 60 & 4 & 40.00 \\
15 & 200 & 50 & 6 & 50.17 \\
16 & 200 & 50 & 54.5 & 54.55 \\
\hline
\end{tabular}

actual experimental results with trivial trial error. In the regression model, the three one-time terms $(A, B$, and $C)$, one interaction terms $(B C)$, and the three quadratic terms $\left(A^{2}, B^{2}\right.$, and $\left.C^{2}\right)$ showed significant effects on the experimental results. Therefore, the established regression equation model could be used to assess the test results due to the high correlation between predicted and observed values $\left(R^{2}=0.9931\right)$, indicating the high reliability of the regression equation model. The trivial difference between the goodness-of-fit $\left(R^{2}\right)$ and adjusted $R^{2}$ suggested the high reliability of the established regression model of nitrite adsorption by $\mathrm{CS}-\mathrm{FeO}$, while the high reliability of the regression model was also supported by the low value $(0.0231)$ of the coefficient of variation (Table 3 ).

3.3.2. Interaction of Factors. The RSM plot is a flat and a three-dimensional space surface plot constructed by the interaction of response values corresponding to each factor of $A, B$, and $C$, which allows the visualization of the effect of the interaction of each pair of two factors on the tested results (Figure 8). The contour line intuitively reflects the effect of the interaction of each factor on the response value, and the oval indicates that the interaction of each pair of two factors is significant, while the circle indicates the opposite effect [61].

Our results showed that the effects of the interactive relationships of $B C$ but not $A C$ and $A B$ on the adsorption of nitrite by $\mathrm{CS}-\mathrm{FeO}$ were significant, suggesting that with fixed value of the amount of CS-FeO (factor $A$ ), the adsorption of nitrite by $\mathrm{CS}-\mathrm{FeO}$ would be significantly affected by the changes of the adsorption temperature (factor $B$ ) and time (factor $C$ ). Taking the results of the ANOVA and the reliability analysis of the established regression model of the adsorption of nitrite by CS-FeO (Tables 2 and 3), it was concluded that the effects of the three factors, i.e., the amount of $\mathrm{CS}-\mathrm{FeO}(A)$, the adsorption temperature $(B)$, and the adsorption time $(C)$, were ranked in the order of $B$ $>C>A$. These results were consistent with those reported by Fu et al. [62], showing that the effects of reaction temperature on the adsorption rate by the chitosan magnetic microspheres were greater than those of reaction time.

3.3.3. Optimization and Validation of the Synthesis Process of $\mathrm{CS}-\mathrm{FeO}$. In order to find the code value of the optimal points of factors $A, B$, and $C$ in the established regression model of the nitrite adsorption by $\mathrm{CS}-\mathrm{FeO}$ with the maximum value of $Y$ (the adsorption rate), we identified the first-order partial derivatives of the three variables of the regression equation with their values to 0 to obtain the ternary linear equation system, which included $1.13-0.25 B-0.29 C-$ $8.10 A=0, \quad 1.58-0.25 A-1.30 C-14.18 B=0$, and $1.46-$ $0.29 A-1.30 B-5.41 C=0$. The results showed that the optimum parameters were as follows: the adsorbent dosage of $237.152 \mathrm{mg}$, the adsorption temperature of $49.388^{\circ} \mathrm{C}$, and the adsorption time of $5.145 \mathrm{~h}$. Considering the convenience of practical operation, the parameters were modified as adsorbent dosage $237 \mathrm{mg}$, adsorption temperature $49^{\circ} \mathrm{C}$, and adsorption time $5.1 \mathrm{~h}$. In order to verify these conditions, three parallel tests were carried out with the modified parameters. Results showed that the nitrite adsorption rate was $65.83 \pm 0.76 \%$, which fell into the range of the theoretically predicted values of nitrite adsorption rate by $\mathrm{CS}-\mathrm{FeO}$ (63.14\% to $66.63 \%$ ) under optimal conditions, indicating that the mathematical model established in our study was highly reliable. Wahid et al. synthesized aminated silica carbon nanotubes (ASCNT) to remove nitrite with a removal rate of $85 \%$ [63]. Similarly, Mirzayi et al. synthesized magnetohematite nanoparticles (MNP) with a nitrite adsorption 
TABLE 2: Results of ANOVA of the established regression model of nitrite adsorption by CS-FeO. Symbols “*” and “**” indicate significant difference set at $P<0.05$ and $P<0.01$, respectively. Sources (factors) $A, B$, and $C$ represent the amount of adsorbent, the adsorption temperature, and adsorption time, respectively.

\begin{tabular}{|c|c|c|c|c|c|}
\hline Source & $\mathrm{df}$ & Sum of squares & Mean squares & $F$ value & $P$ value \\
\hline Model & 9 & 1418.61 & 157.62 & 112.69 & $<0.0001^{* *}$ \\
\hline$A$ & 1 & 10.19 & 10.19 & 7.29 & $0.0307^{*}$ \\
\hline$B$ & 1 & 19.85 & 19.85 & 14.19 & $0.0070^{* *}$ \\
\hline$C$ & 1 & 17.07 & 17.07 & 12.20 & $0.0101^{*}$ \\
\hline$A B$ & 1 & 0.25 & 0.25 & 0.1787 & 0.6852 \\
\hline$A C$ & 1 & 0.34 & 0.34 & 0.2453 & 0.6355 \\
\hline$B C$ & 1 & 6.76 & 6.76 & 4.83 & $0.0439^{*}$ \\
\hline$A^{2}$ & 1 & 276.26 & 276.26 & 197.51 & $<0.0001^{* *}$ \\
\hline$B^{2}$ & 1 & 846.71 & 846.71 & 605.33 & $<0.0001^{* *}$ \\
\hline$C^{2}$ & 1 & 123.10 & 123.10 & 88.01 & $<0.0001^{* *}$ \\
\hline Residual & 7 & 9.79 & 1.40 & & \\
\hline Lack of fit & 3 & 5.89 & 1.96 & 2.01 & 0.1115 \\
\hline Pure error & 4 & 3.91 & 0.9764 & & \\
\hline Corrected total sum of squares & 16 & 1428.40 & & & \\
\hline
\end{tabular}

TABLE 3: Reliability analysis of the established regression model of nitrite adsorption by $\mathrm{CS}-\mathrm{FeO}$.

\begin{tabular}{lcccc}
\hline Project & Mean & $R^{2}$ & Adjusted $R^{2}$ & Coefficient of variation \\
\hline Result & 51.16 & 0.9931 & 0.9843 & 0.0231 \\
\hline
\end{tabular}

rate of $88 \%$ under the optimal conditions [64]. Furthermore, Diriba et al. reported that under the optimal conditions, the nitrite adsorption rate reached $90 \%$ on treated bagasse [65]. However, it was noted that the high nitrite adsorption rates were obtained under the condition of low $\mathrm{pH}$ values (i.e., 25). In our study, the nitrite adsorption rate of CS-FeO reached more than $85 \%$ under the condition of $\mathrm{pH}$ value of 3, which was similar to the adsorption rates reported in the previous studies. Furthermore, our preliminary observations showed that the $\mathrm{CS}-\mathrm{FeO}$ maintained sound stability at low $\mathrm{pH}$ of 3. In comparison to these results, our study revealed that the $\mathrm{CS}-\mathrm{FeO}$ showed slightly lower nitrite adsorption rate but with the $\mathrm{pH}$ values of nearly neutral (i.e., 6-8), indicating that the adjustment of $\mathrm{pH}$ value was not required and significantly reducing the cost of adsorption treatment in practical applications.

3.4. Regeneration of $\mathrm{CS}-\mathrm{FeO}$. The reusability of $\mathrm{CS}-\mathrm{FeO}$ was investigated based on the results of the regeneration experiments of CS- $\mathrm{FeO}$ with three different types of eluents, i.e., $\mathrm{NaOH}, \mathrm{Na}_{2} \mathrm{SO}_{4}$, and $\mathrm{NaCl}$ (Figure 9). Compared with the adsorption rate before regeneration, the adsorption rate was greatly reduced after each regeneration of $\mathrm{CS}-\mathrm{FeO}$ with either $\mathrm{NaOH}$ or $\mathrm{NaCl}$ as eluents. For example, the adsorption rate of nitrite by $\mathrm{CS}-\mathrm{FeO}$ decreased by over $50 \%$ in 5 and 3 regenerations with $\mathrm{NaOH}$ and $\mathrm{NaCl}$ as eluents, respectively, while after 6 times of regeneration, the adsorption rate of nitrite by $\mathrm{CS}-\mathrm{FeO}$ with $\mathrm{NaOH}$ and $\mathrm{NaCl}$ as eluents decreased from $65.76 \pm 0.54 \%$ to $22.47 \pm 0.60 \%$ and $5.47 \pm$ $0.85 \%$, respectively. However, after 5 times regeneration of CS- $\mathrm{FeO}$ with $\mathrm{Na}_{2} \mathrm{SO}_{4}$ as eluent, no significant decrease in the nitrite adsorption rate was observed between each regeneration. Although the nitrite adsorption rate was significantly decreased after 6 times of regeneration in comparison to that of 5 times of regeneration with $\mathrm{Na}_{2} \mathrm{SO}_{4}$ as eluent, the adsorption of nitrite by CS-FeO with $\mathrm{Na}_{2} \mathrm{SO}_{4}$ as eluent was still much higher than that with either $\mathrm{NaOH}$ or $\mathrm{NaCl}$ as eluents. Furthermore, after each regeneration, the amount of CS-FeO lost by less than $2 \%$ of the initial contents with $\mathrm{Na}_{2} \mathrm{SO}_{4}$ as eluent. These results indicated that $\mathrm{CS}-\mathrm{FeO}$ showed the best regeneration performance with $\mathrm{Na}_{2} \mathrm{SO}_{4}$ as the eluent. Studies have shown that a novel type of nanomaterials synthesized by grafting porphyrin onto $\mathrm{FeO}$ was used to remove nitrite from water sources, showing high adsorption rate $(80 \%)$ after 5 times of regeneration with $\mathrm{NaOH}$ as the eluents [66]. However, the cost of synthesizing this type of nanomaterial was much higher due to its highly complex preparation procedures and requirements of costly material (i.e., porphyrin) than that of preparing the CS-FeO in our study, making it difficult to adopt this type of nanomaterials in practical application. Moreover, anthracite has also been used to remove the nitrite from the water sources [13]. Result showed that the adsorption of nitrite by anthracite maintained at $85 \%$ after 4 times of regeneration with $\mathrm{HCl}$ as eluents. Furthermore, the CS solely showed no adsorption effect on nitrite. Therefore, it is speculated that both porphyrin and anthracite are involved in the adsorption of nitrite, i.e., showing the surface adsorption mechanisms. Furthermore, due to their larger surface areas than CS-FeO, both porphyrin and anthracite were capable of generating higher adsorption rate of nitrite than $\mathrm{CS}-\mathrm{FeO}$ $[13,66]$. Although the CS-FeO showed lower adsorption rate of nitrite than anthracite, CS-FeO demonstrated strong 
$\mathrm{AB}$

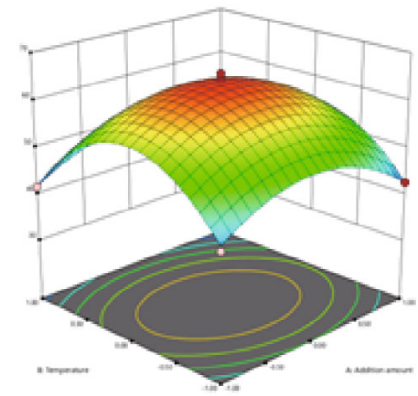

$\mathrm{AC}$

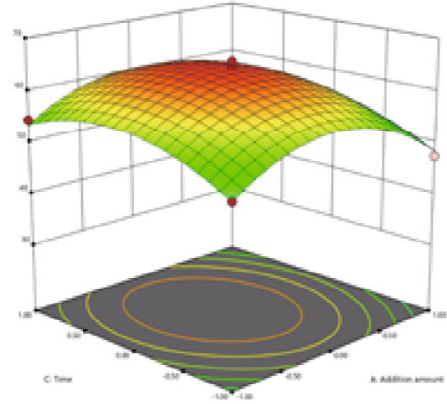

$\mathrm{BC}$

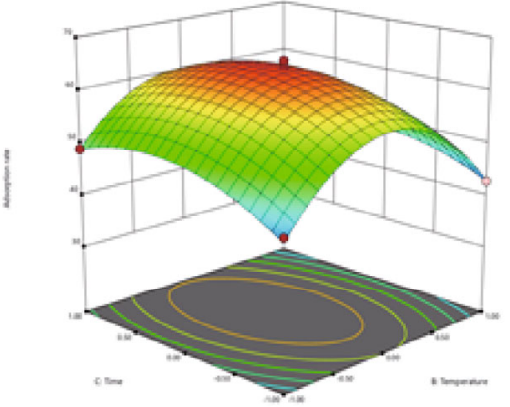

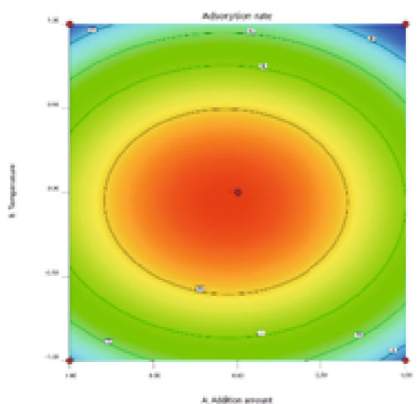
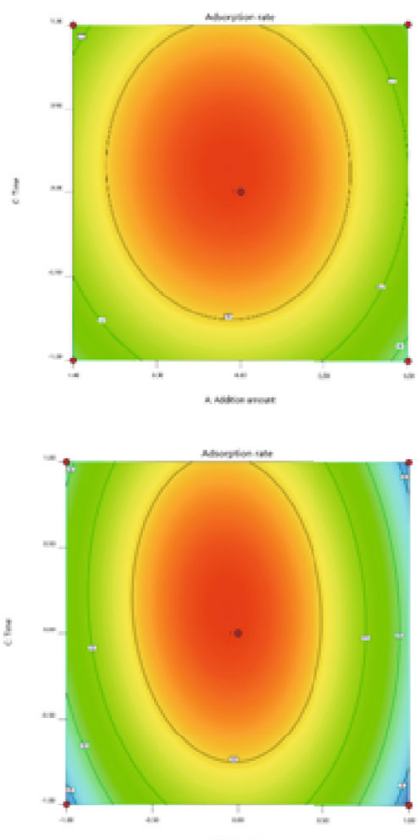

FIGURE 8: Response surfaces and contour plots of the pairwise interactive effects on the adsorption of nitrite by CS-FeO of the amount of CS$\mathrm{FeO}$ (factor $A$ ), the adsorption of temperature (factor $B$ ), and the adsorption time (factor $C$ ).

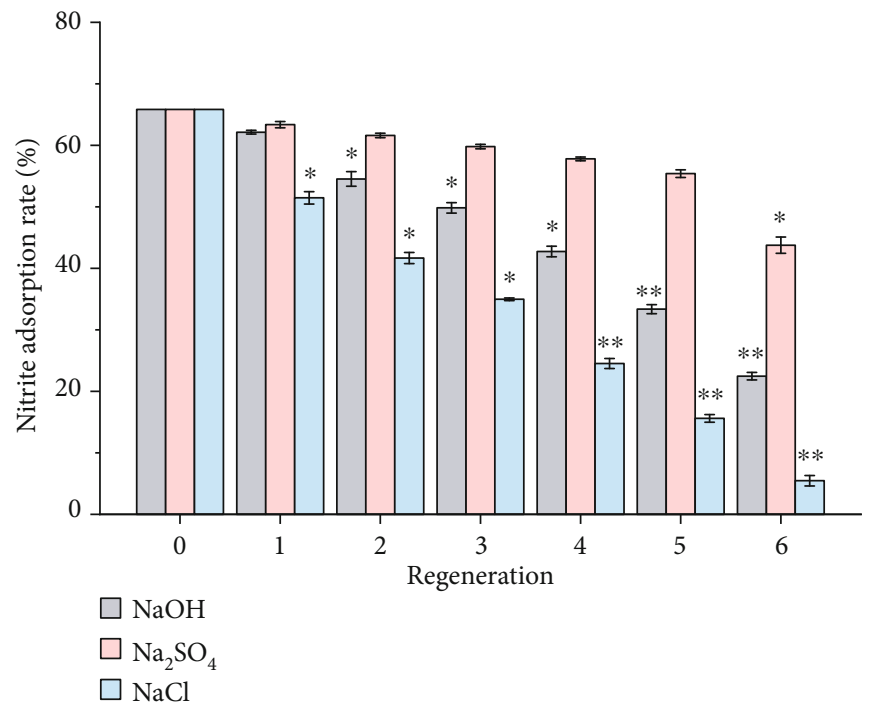

Figure 9: Effect of different eluents (i.e., $\mathrm{NaOH}, \mathrm{Na}_{2} \mathrm{SO}_{4}$, and $\mathrm{NaCl}$ ) on nitrite adsorption rate after regeneration of CS-FeO. Symbols “*” and “**” indicate significant difference set at $P<0.05$ and $P<0.01$, respectively, in comparison to the nitrite adsorption rate prior to regeneration. 
magnetic separation, making it much easier to recycle the $\mathrm{CS}-\mathrm{FeO}$ (i.e., with the external magnetic field) than the anthracite. Therefore, compared with anthracite, the recovery cost of adsorption materials in practical application is highly reduced for the use of $\mathrm{CS}-\mathrm{FeO}$ as the adsorbents.

\section{Conclusion}

In this study, we synthesized and characterized the CSderived magnetic nanomaterial (CS-FeO) and identified its optimal conditions of nitrite removal. CS-FeO was a black crystalline powder with high crystallinity and thermal stability in the temperature range of 50 to $200^{\circ} \mathrm{C}$. CS-FeO showed high magnetism and could be easily and quickly separated from aqueous solution under the action of external magnetic field. The energy dispersive spectral data showed that the structural and functional groups of CS maintained in the molecular structure of CS-FeO, forming a core-shell structure with $\mathrm{FeO}$ as the core and $\mathrm{CS}$ as the shell. Furthermore, under the optimal conditions, the adsorption rate of nitrite by $\mathrm{CS}-\mathrm{FeO}$ reached $65.83 \pm 0.76 \%$. Moreover, $\mathrm{CS}-\mathrm{FeO}$ demonstrated strong regeneration performance with $\mathrm{Na}_{2} \mathrm{SO}_{4}$ used as eluent. These results indicated that $\mathrm{CS}-\mathrm{FeO}$ could be potentially used as an efficient and cost-effective adsorbent for nitrite removal from drinking water sources and industrial wastewater.

\section{Data Availability}

Data are available from the corresponding authors upon request.

\section{Disclosure}

The funders had no role in the design of the study; in the collection, analyses, or interpretation of data; in the writing of the manuscript; or in the decision to publish the results.

\section{Conflicts of Interest}

The authors declare no conflict of interest.

\section{Authors' Contributions}

Tong Liu and Jingyi Fu contributed equally to this work.

\section{Acknowledgments}

This research was funded by the Industrial Technology Research and Development Project of Jilin Province Development and Reform Commission (2020C027-5) and the Scientific Research and Cultivation Project of Changchun University (ZKQ201911).

\section{References}

[1] M. Q. Qiu, B. W. Hu, Z. S. Chen, H. Yang, L. Zhuang, and X. K. Wang, "Challenges of organic pollutant photocatalysis by biochar-based catalysts," Biochar, vol. 3, no. 2, pp. 117-123, 2021.
[2] M. J. Hao, M. Q. Qiu, H. Yang, B. W. Hu, and X. G. Wang, "Recent advances on preparation and environmental applications of MOF-derived carbons in catalysis," Science of the Total Environment, vol. 760, p. 143333, 2021.

[3] X. L. Liu, R. Ma, L. Zhuang et al., "Recent developments of doped g-C3N4photocatalysts for the degradation of organic pollutants," Critical Reviews in Environmental Science and Technology, vol. 51, no. 8, pp. 751-790, 2021.

[4] L. Yao, H. Yang, Z. S. Chen, M. Q. Qiu, B. W. Hu, and X. X. Wang, "Bismuth oxychloride-based materials for the removal of organic pollutants in wastewater," Chemosphere, vol. 273, p. 128576, 2021.

[5] A. Choodum, J. Tiengtum, T. Taweekarn, and W. Wongniramaikul, "Convenient environmentally friendly on-site quantitative analysis of nitrite and nitrate in seawater based on polymeric test kits and smartphone application," Spectrochimica Acta. Part A, Molecular and Biomolecular Spectroscopy, vol. 243, p. 118812, 2020.

[6] J. Wang, H. Tang, X. Zhang et al., "Mitigation of nitrite toxicity by increased salinity is associated with multiple physiological responses: A case study using an economically important model species, the juvenile obscure puffer (Takifugu obscurus)," Environmental Pollution, vol. 232, pp. 137-145, 2018.

[7] S. Khademikia, Z. Rafiee, M. M. Amin, P. Poursafa, M. Mansourian, and A. Modaberi, "Association of nitrate, nitrite, and total organic carbon (TOC) in drinking water and gastrointestinal disease," Journal of Nanomaterials, vol. 2013, Article ID 603468, 4 pages, 2013.

[8] Q. Jiang, W. Zhang, H. Tan et al., “Analysis of gene expression changes, caused by exposure to nitrite, in metabolic and antioxidant enzymes in the red claw crayfish,_Cherax quadricarinatus_," Ecotoxicology and Environmental Safety, vol. 104, pp. 423-428, 2014.

[9] K. Katabami, M. Hayakawa, and S. Gando, "Severe methemoglobinemia due to sodium nitrite poisoning," Journal of Nanomaterials, vol. 2016, Article ID 9013816, 3 pages, 2016.

[10] W. A. H. Altowayti, H. G. A. Allozy, S. Shahir, P. S. Goh, and M. Yunus, "A novel nanocomposite of aminated silica nanotube (MWCNT/Si/NH $\mathrm{NH}_{2}$ ) and its potential on adsorption of nitrite," Environemental Science and Pollution Research, vol. 26, no. 28, pp. 28737-28748, 2019.

[11] Q. Wang, L. Yu, Y. Liu et al., "Methods for the detection and determination of nitrite and nitrate: a review," Talanta, vol. 165, pp. 709-720, 2017.

[12] P. Singh, Y. R. Beg, and G. R. Nishad, "A review on spectroscopic methods for determination of nitrite and nitrate in environmental samples," Talanta, vol. 191, pp. 364-381, 2019.

[13] J. He, J. Guo, Q. Zhou, and F. Fang, "Adsorption characteristics of nitrite on natural filter medium: kinetic, equilibrium, and site energy distribution studies," Ecotoxicology and Environmental Safety, vol. 169, pp. 435-441, 2019.

[14] J. Liu, X. Cheng, Y. Zhang, X. Wang, Q. Zou, and L. Fu, "Zeolite modification for adsorptive removal of nitrite from aqueous solutions," Microporous and Mesoporous Materials, vol. 252, pp. 179-187, 2017.

[15] A. Miyazaki, T. Asakawa, and I. Balint, " $\mathrm{NO}_{2}{ }^{-}$adsorption onto denitration catalysts," Applied Catalysis A: General, vol. 363, no. 1-2, pp. 81-85, 2009.

[16] D. Wan, H. Liu, R. Liu, J. Qu, S. Li, and J. Zhang, "Adsorption of nitrate and nitrite from aqueous solution onto calcined 
(mg-al) hydrotalcite of different mg/al ratio," Chemical Engineering Journal, vol. 195, pp. 241-247, 2012.

[17] J. Yao, Q. N. Kong, H. Zhu, Y. Long, and D. Shen, “Adsorption characteristics of nitrite on friedel's salt under the landfill circumstance," Chemical Engineering Journal, vol. 254, pp. 479485, 2014.

[18] F. Ogata, A. Ueda, S. Tanei, D. Imai, and N. Kawasaki, "Simultaneous removal of phosphate and nitrite ions from aqueous solutions using modified soybean waste," Journal of Industrial and Engineering Chemistry, vol. 35, pp. 287-294, 2016.

[19] H. Li and C. Yang, "Nitrite removal using ion exchange resin: batch vs. fixed bed performance," Separation Science and Technology, vol. 50, no. 11, pp. 1721-1730, 2015.

[20] H. Yue, L. Xue, and F. Chen, "Efficiently electrochemical removal of nitrite contamination with stable $\mathrm{RuO}_{2}-\mathrm{TiO}_{2} / \mathrm{Ti}$ electrodes," Applied Catalysis B: Environmental, vol. 206, pp. 683-691, 2017.

[21] D. Wei, K. Zhang, H. H. Ngo et al., "Nitrogen removal via nitrite in a partial nitrification sequencing batch biofilm reactor treating high strength ammonia wastewater and its greenhouse gas emission," Bioresource Technology, vol. 230, pp. 49-55, 2017.

[22] Y. Zou, M. Lin, W. Xiong et al., "Metagenomic insights into the effect of oxytetracycline on microbial structures, functions and functional genes in sediment denitrification," Ecotoxicology and Environmental Safety, vol. 161, pp. 85-91, 2018.

[23] H. Qian, Z. Zhao, J. C. Velazquez, L. A. Pretzer, and M. S. Wong, "Supporting palladium metal on gold nanoparticles improves its catalysis for nitrite reduction," Nanoscale, vol. 6, pp. 358-364, 2013.

[24] Y. Lu, X. Lu, W. Shu, J. Zhou, and G. Qian, "Microbial mediated iron redox cycling in fe (hydr) oxides for nitrite removal," Bioresource Technology, vol. 224, pp. 34-40, 2016.

[25] J. Liu, S. Wang, J. Fu, X. Ding, and J. Zhao, “ $\mathrm{Zn}^{2+}$ adsorption from wastewater using a chitosan $/ \beta$ yclodextrin-based composite membrane," Journal of Food Biochemistry, vol. 44, article E13483, 2020.

[26] Z. Zhang and H. Cui, "Biodegradability and biocompatibility study of Poly(Chitosan-g-lactic acid) scaffolds," Molecules, vol. 17, no. 3, pp. 3243-3258, 2012.

[27] G. Kyzas and E. Deliyanni, "Mercury(II) removal with modified magnetic chitosan adsorbents," Molecules, vol. 18, no. 6, pp. 6193-6214, 2013.

[28] J. Weißpflog, A. Gündel, D. Vehlow et al., "Solubility and selectivity effects of the anion on the adsorption of different heavy metal ions onto chitosan," Molecules, vol. 25, no. 11, p. 2482, 2020.

[29] J. Zhang, Y. Wang, D. Liang, Z. Xiao, and J. Li, "Sulfhydrylmodified chitosan aerogel for the adsorption of heavy metal ions and organic dyes," Industrial and Engineering Chemistry Research, vol. 59, no. 32, pp. 14531-14536, 2020.

[30] K. Yang, G. Wang, F. Liu, X. Wang, and X. Chen, "Removal of multiple heavy metal ions using a macromolecule chelating flocculant xanthated chitosan," Water Science and Technology, vol. 79, no. 12, pp. 2289-2297, 2019.

[31] D. H. K. Reddy and S. M. Lee, "Application of magnetic chitosan composites for the removal of toxic metal and dyes from aqueous solutions," Advances in colloid and interface science, vol. 201, pp. 68-93, 2013.

[32] A. Ali, H. Zafar, M. Zia et al., "Synthesis, characterization, applications, and challenges of iron oxide nanoparticles,"
Nanotechnology, science and applications, vol. Volume 9, pp. 49-67, 2016.

[33] H. M. Pathan, R. S. Mane, Y. A. Ismail, A. Subramania, W. Ramadan, and S. D. Bhagat, "Functional nanomaterials," Journal of Nanotechnology, vol. 2012, Article ID 732368, 2 pages, 2012.

[34] Z. Lin, Y. Xu, Z. Zhen et al., "Application and reactivation of magnetic nanoparticles in _Microcystis aeruginosa_ harvesting," Bioresource Technology, vol. 190, pp. 82-88, 2015.

[35] M. T. Pelegrino, J. C. Pieretti, G. Nakazato, M. C. Gonçalves, J. C. Moreira, and A. B. Seabra, "Chitosan chemically modified to deliver nitric oxide with high antibacterial activity," Nitric Oxide, vol. 106, pp. 24-34, 2021.

[36] C. Yang, W. Guo, L. Cui et al., "pH-responsive magnetic coreshell nanocomposites for drug delivery," Langmuir, vol. 30, no. 32, pp. 9819-9827, 2014.

[37] T. Ma and P. Liu, "Fabrication and Thermal Degradation Kinetics of $\mathrm{PBT} / \mathrm{BEO} / \mathrm{Nano}-\mathrm{Sb} 2 \mathrm{O} 3$ Composites," Journal of Nanomaterials, vol. 2020, Article ID 1234269, 10 pages, 2020.

[38] M. An, J. Cui, and L. Wang, "Magnetic recyclable nanocomposite catalysts with good dispersibility and high catalytic activity," Journal of Physical Chemistry C, vol. 118, no. 6, pp. 3062-3068, 2014.

[39] P. Xu, B. Song, H. M. Luo, L. Fei, and H. L. Wang, "Catalyst nanomaterials," Journal of Nanomaterials, vol. 2015, Article ID 514309, 2 pages, 2015.

[40] H. Li, F. Zhou, B. He, G. Wang, W. Xie, and E. Liang, "Efficient adsorption of heavy metal ions by a novel AO-PAN-g-Chitosan/Fe3O4Composite," ChemistrySelect, vol. 5, no. 27, pp. 8033-8039, 2020.

[41] D. Bharathi, R. Ranjithkumar, S. Vasantharaj, B. Chandarshekar, and V. Bhuvaneshwari, "Synthesis and characterization of chitosan/iron oxide nanocomposite for biomedical applications," International Journal of Biological Macromolecules, vol. 132, pp. 880-887, 2019.

[42] Y. H. Sun and Y. Dong, "Study on effects of chitosan to scavenge nitrite," Food Science, vol. 26, pp. 71-73, 2005.

[43] L. Lv, N. Chen, C. Feng, Y. Gao, and M. Li, "Xanthate-modified magnetic chitosan/poly (vinyl alcohol) adsorbent: Preparation, characterization, and performance of $\mathrm{Pb}$ (II) removal from aqueous solution," Journal of the Taiwan Institute of Chemical Engineers, vol. 78, pp. 485-492, 2017.

[44] P. I. P. Soares, D. Machado, C. Laia et al., "Thermal and magnetic properties of chitosan-iron oxide nanoparticles," Carbohydrate polymers, vol. 149, pp. 382-390, 2016.

[45] V. Hastak, S. Bandi, S. Kashyap et al., "Antioxidant efficacy of chitosan/graphene functionalized superparamagnetic iron oxide nanoparticles," Journal of Materials Science, vol. 29, pp. 1-8, 2018.

[46] P. Nehra, R. P. Chauhan, N. Garg, and K. Verma, "Antibacterial and antifungal activity of chitosan coated iron oxide nanoparticles," British journal of biomedical science, vol. 75, pp. 13-18, 2017.

[47] D. Cheng, X. Li, G. Zhang, and H. Shi, "Morphological effect of oscillating magnetic nanoparticles in killing tumor cells," Nanoscale Research Letters, vol. 9, pp. 1-8, 2014.

[48] A. G. Roca, R. Costo, A. F. Rebolledo et al., "Progress in the preparation of magnetic nanoparticles for applications in biomedicine," Journal of Physics D: Applied Physics, vol. 42, no. 22, p. 224002, 2009. 
[49] T. Koutzarova, S. Kolev, C. Ghelev, D. Paneva, and I. Nedkov, "Microstructural study and size control of iron oxide nanoparticles produced by microemulsion technique," Physica Status Solidi C: Current Topics in Solid State Physics, vol. 3, pp. 1302-1307, 2010.

[50] J. Guo, S. Chen, L. Liu, L. Bing, and Y. Feng, "Adsorption of dye from wastewater using chitosan-ctab modified bentonites," Journal of Colloid and Interface Science, vol. 382, no. 1, pp. 61-66, 2012.

[51] Y. Li, J. Chu, J. Qi, and L. Xin, “An easy and novel approach for the decoration of graphene oxide by $\mathrm{Fe}_{3} \mathrm{O}_{4}$ nanoparticles," Applied Surface Science, vol. 257, pp. 6059-6062, 2012.

[52] D. T. Vu, L. Xiang, and C. Wang, "Adsorption of As(III) from aqueous solution based on porous magnetic/chitosan/ferric hydroxide microspheres prepared via electrospraying," Science China Chemistry, vol. 56, no. 5, pp. 678-684, 2013.

[53] C. Cao, L. Xiao, C. Chen, X. Shi, Q. Cao, and L. Gao, "In situ preparation of magnetic $\mathrm{Fe}_{3} \mathrm{O}_{4}$ /chitosan nanoparticles via a novel reduction-precipitation method and their application in adsorption of reactive azo dye," Powder Technology, vol. 260, pp. 90-97, 2014.

[54] J. Shi, C. Cheng, H. Zhao, J. Jing, N. Gong, and W. Lu, “_In vivo_ anti-radiation activities of the _Ulva pertusa_ polysaccharides and polysaccharide -iron(III) complex," International Journal of Biological Macromolecules, vol. 60, pp. 341-346, 2013.

[55] X. Yang, M. Huang, C. Qin, B. Lv, Q. Mao, and Z. Liu, "Structural characterization and evaluation of the antioxidant activities of polysaccharides extracted from qingzhuan brick tea," International Journal of Biological Macromolecules, vol. 101, pp. 768-775, 2017.

[56] M. Karpuraranjith and S. Thambidurai, "Chitosan/zinc oxidepolyvinylpyrrolidone (cs/zno-pvp) nanocomposite for better thermal and antibacterial activity," International Journal of Biological Macromolecules, vol. 104, no. Part B, pp. 17531761, 2017.

[57] S. Vasantharaj, N. Sripriya, M. Shanmugavel, E. Manikandan, and P. Senthilkumar, "Surface active gold nanoparticles biosynthesis by new approach for bionanocatalytic activity," Journal of Photochemistry and Photobiology B, vol. 179, pp. 119-125, 2018.

[58] L. Zhou, C. Shang, Z. Liu, G. Huang, and A. A. Adesina, "Selective adsorption of uranium(VI) from aqueous solutions using the ion- imprinted magnetic chitosan resins," Journal of Colloid and Interface Science, vol. 366, no. 1, pp. 165-172, 2012.

[59] A. Kumar, T. Gupta, S. S. Kakan, S. Kalidhasan, V. Rajesh, and N. Rajesh, "Effective adsorption of hexavalent chromium through a three center (3c) co-operative interaction with an ionic liquid and biopolymer," Journal of Hazardous Materials, vol. 239, pp. 213-224, 2012.

[60] A. S. K. Krishna and S. J. Jiang, "Chitosan-functionalized graphene oxide: a novel adsorbent an efficient adsorption of arsenic from aqueous solution," Journal of Environmental Chemical Engineering, vol. 4, pp. 1698-1713, 2016.

[61] S. Zhang, J. Xi, and C. Wang, "High hydrostatic pressure extraction of flavonoids from propolis," Journal of Chemical Technology \& Biotechnology: International Research in Process, Environmental \& Clean Technology, vol. 80, pp. 50-54, 2005.

[62] M. Fu, W. Lin, Z. Chen, B. Zheng, and X. Hu, "Preparation of magnetic chitosan microspheres and research on its adsorption behavious," New Chem Mater, vol. 43, pp. 145-147, 2015.
[63] W. Altowayti, H. Allozy, S. Shahir, S. G. Pei, and M. Yunus, “A novel nanocomposite of aminated silica nanotube (mwcnt/si/nh 2) and its potential on adsorption of nitrite," Environemental Science and Pollution Research, vol. 26, no. 28, pp. 28737-28748, 2019.

[64] B. Mirzayi, A. Nematollahzadeh, F. Firouznia, and S. Heydari, "Nitrite removal from aqueous solution using surface modified maghemite nanoparticles," Nano, vol. 9, no. 2, p. 1450013, 2014.

[65] D. Diriba, A. Hussen, and V. R. Maheswara, "Removal of nitrite from aqueous solution using sugarcane bagasse and wheat straw," Bulletin of environmental contamination and toxicology, vol. 93, no. 1, pp. 126-131, 2014.

[66] T. Poursaberi, S. Ghadernia, M. Hassanisadi, K. Torkestani, and M. Mirrahimi, "Efficient separation of nitrite from aqueous solutions by grafting metalloporphyrin on $\mathrm{Fe}_{3} \mathrm{O}_{4}$ nanoparticles," Journal of the Iranian Chemical Society, vol. 10, no. 1, pp. 13-20, 2013. 